\title{
Swine model of in-stent stenosis in the iliac artery evaluating the serial time course
}

\author{
Osamu ISHIKAWA ${ }^{1)}$, Minoru TANAKA ${ }^{2)}$, Kenjiro KONNO ${ }^{3)}$, Terumitsu HASEBE ${ }^{4}$, \\ Ayumi HORIKAWA ${ }^{2)}$, Akira IIJIMA ${ }^{1)}$, Nobuhito SAITO $^{1)}$, and Koki TAKAHASHI ${ }^{2)}$ \\ ${ }^{1)}$ Department of Neurosurgery, The University of Tokyo Hospital, 7-3-1 Hongo, Bunkyo-ku, Tokyo 113-8655, Japan \\ ${ }^{2)}$ Department of Transfusion Medicine, The University of Tokyo Hospital, 7-3-1 Hongo, Bunkyo-ku, Tokyo 113-8655, \\ Japan \\ ${ }^{3)}$ Center for iPS Cell Research and Application, Kyoto University, 53 Kawahara-cho, Shogoin, Sakyo-ku, Kyoto \\ 606-8507, Japan \\ 4) Department of Radiology, Tokai University Hachioji Hospital, 1838 Ishikawa-machi, Hachioji-shi, Tokyo $192-$ \\ 0032, Japan
}

\begin{abstract}
The aim of this study was to propose a new animal model evaluating the serial time course of in-stent stenosis by repeated carotid artery catheterization in the same animal. 16 bare-metal stents were implanted in the normal external and internal iliac artery of 8 miniature pigs. Repeated measurements were performed in the same animal every 2 weeks for 12 weeks through carotid artery catheterization. The time course and peak neointimal proliferation were evaluated by intravascular ultrasound. Health of all animals was assessed by clinical and hematological examinations. As a result, 7 times of carotid artery catheterization was performed per pig, but all animals remained healthy without both any complications and hematological inflammatory abnormalities. The time course of neointimal proliferation of each stent was observed from the stage of hyperplasia to partial regression. The peak neointimal proliferation varied from 6 to 12 weeks despite implantation of identical stents using the same deployment method. In conclusion, repeated carotid artery catheterization to the same animal is feasible without animal health deterioration. This model should be useful to evaluate the time course of neointimal proliferation after stent deployment in preclinical study.
\end{abstract}

Key words: experimental study, in-stent stenosis, intravascular ultrasound, swine model

\section{Introduction}

It is essential to evaluate new stent devices which are implanted in human coronary, peripheral and carotid arteries by conducting preclinical studies [14-16]. Pig and rabbit models have been widely used to evaluate in-stent stenosis by pathological analysis as well as simultaneous "one-shot" angiography and/or intravascular ultrasound (IVUS) [3, 5, 10, 12, 14-16]. In these models, in-stent stenosis was evaluated at stent implantation and a second time at final follow-up, but serial evaluations during follow-up were not performed. In these studies, the time course of in-stent stenosis needed to be evaluated by comparing different group of animals at each time point.

Serial measurements in the same animal should pro-

(Received 22 February 2018 / Accepted 3 June 2018 / Published online in J-STAGE 1 August 2018)

Address corresponding: O. Ishikawa, Department of Neurosurgery, The University of Tokyo Hospital, 7-3-1 Hongo, Bunkyo-ku, Tokyo 113-8655, Japan 
vide useful information on the time course of neointimal proliferation, and should make it possible to determine peak neointimal proliferation. However, such studies have not been reported previously. The objectives of this study were to establish the feasibility and safety of repeated in-stent measurements in the same animal, and then to evaluate the time course of neointimal proliferation after implantation of a bare-metal stent (BMS) in iliac arteries of miniature pigs.

\section{Materials and Methods}

\section{Animal preparation}

Göttingen minipigs (Ellegaard, Dalmose, Denmark) were used for this study. All animals were fed a normal diet without cholesterol supplementation. No additional antiplatelet medication was given during the study. All animal research procedures were performed in accordance with the Animal Use Guidelines of our university.

All experimental procedures were performed in a standard manner [2, 11, 14-16, 22]. For premedication, the minipigs received an intramuscular injection consisting of midazolam $(0.5 \mathrm{mg} / \mathrm{kg}$, Astellas, Tokyo, Japan) and xylazine $(2.0 \mathrm{mg} / \mathrm{kg}$, Bayer, Leverkusen, Germany), and were orally intubated and then artificially ventilated (Pro-45, Acoma, Tokyo, Japan). A veterinarian (K.K.) maintained general anesthesia by inhalation of oxygen containing $0.5-1.5 \%$ isoflurane (Dainippon Sumitomo Pharma, Osaka, Japan). Lactated Ringer's solution was dripped intravenously through the ear vein. Arterial blood pressure, heart rate, electrocardiogram, oxygen saturation and rectal temperature were continuously monitored throughout the procedure. Cefmetazole sodium (1 g, Daiichisankyo, Tokyo, Japan) was administered intravenously twice soon after securing vascular access and at the end of the procedure.

\section{Surgical procedures}

Under sterile conditions, a longitudinal skin incision approximately $5 \mathrm{~cm}$ long was first created along the anterior border of the left sternomastoid muscle. Then the left common carotid artery was exposed by sharp dissection, and a $7 \mathrm{Fr}$ sheath-introducer (Medikit Super Sheath 7 Fr; Medikit, Tokyo, Japan) was inserted in a retrograde direction after penetration of the anterior arterial wall with the puncture needle. Hematological examination was performed on a blood sample $(\sim 5 \mathrm{ml})$ collected from the sheath-introducer, and then an intra- venous bolus of $100 \mathrm{U} / \mathrm{kg}$ of heparin (Ajinomoto, Tokyo, Japan) was administered, followed by additional boluses of $40 \mathrm{U} / \mathrm{kg}$ every hour to prevent the blood coagulation. At the end of the operation, the sheath-introducer was removed and the insertion hole was sutured using Nylon 5-0 suture. The muscle and skin were closed layer by layer, and 2\% lidocaine gel (Aspen Japan, Tokyo, Japan) was applied to the wound to relieve postoperative pain.

\section{Stent implantation}

A bare-metal stent (BMS; KW39 stent, Kawasumi Laboratories, Inc., Tokyo, Japan) is a balloon-expandable stent made with stainless steel (SUS316L) and has a length of $12 \mathrm{~mm}$ [19].[REMOVED HYPERLINK FIELD]

The procedures were performed under angiographic guidance using a clinical C-arm X-ray imaging system (ARCADIS Avantic, Siemens, Munich, Germany). Distal abdominal aortography was performed with a $7 \mathrm{Fr}$ guiding catheter (Envoy, Cordis, Miami, FL, USA). For optimum stent deployment, the size of each iliac artery was measured by intravascular ultrasound (IVUS; iLab, Boston Scientific, Natick, MA, USA) after $0.2 \mathrm{mg}$ nitroglycerin was administered intra-arterially through a 2.1 Fr microcatheter (Tangent, Kawasumi Laboratories, Inc., Tokyo, Japan). Based on the compliance table of the stent delivery system for humans (nominal pressure, 8 to 10 atm), an optimal inflation pressure was selected to achieve a stent/artery ratio of 1.0 to $1.1[15,16]$. A balloon catheter with a BMS was placed in the external iliac artery (EIA), and then the stent was deployed by inflating the balloon for $1 \mathrm{~min}$. Angiography and IVUS imaging were performed after stent implantation. Subsequently, another BMS was implanted in the contralateral internal iliac artery (IIA) in the same manner. Although a new kind of stent under development was implanted in the contralateral EIA and ipsilateral IIA, the data on these coated stents are not included in this report, since we want to focus on the feasibility of repeated IVUS measurements in the stented vessels through carotid artery catheterization.

\section{Follow-up procedures}

After stent implantation, IVUS imaging were performed every 2 weeks for 12 weeks. At each follow-up time point, general anesthesia was induced, and the antibiotics was given intravenously twice in the same man- 
ner as first operation. The skin was incised at the same location that was used for the previous catheterization, with slight extension to the proximal site. The left common carotid artery was exposed again, and a 6 Fr sheathintroducer was inserted in the proximal portion of the artery which was free of tissue adhesions followed by penetration of the arterial wall with the puncture needle. After IVUS measurements in the iliac arteries, the carotid artery was repaired in the same manner as used for the initial procedure. If the sheath-introducer insertion position reached the junction of the left and right carotid arteries, the right common carotid artery was used instead of the left at the next scheduled follow-up time point.

\section{Animal health assessment}

Since the repeated procedures might affect animal health, physical and neurological conditions of the minipigs were evaluated using a modified neurological grading scale $[20,24]$, which assessed appetite (0 to 4 points), standing position (0 to 5 ), head position ( 0 to 2 ), utterance (0 to 2), motor function (fore- and hindlimbs; 0 to $4 \times 2$ ), and facial paresis ( 0 to 1$)$. The total score ranged from 0 to 22 points. Animal body weight was measured every 2 weeks. Serum levels of hypersensitive C-reactive protein (hs-CRP) and tumor necrosis factor (TNF) -alpha were measured to evaluate infection before stent deployment and at each follow-up time point.

\section{IVUS imaging protocol and quantitative analysis}

A standard IVUS imaging protocol was applied [7, 11, 22]. All IVUS images were acquired using a commercially-available system (iLab, Boston Scientific, Natick, MA, USA) incorporating a $40 \mathrm{MHz}$ single-element transducer rotating at $1,800 \mathrm{rpm}$ within a $3.2 \mathrm{Fr}$ short monorail imaging sheath (Atlantis SR Pro, Boston Scientific). IVUS imaging was performed from the distal to proximal portion of the stented segment using automatic pullback at $0.5 \mathrm{~mm} / \mathrm{s}$. All IVUS images were stored on a DVD for offline analysis.

A coauthor blinded to the purpose of the study performed quantitative IVUS analysis. The cross-sectional area of each in-stent segment was measured at 1-mm intervals using validated software (iReview, Boston Scientific) $[11,21,22]$. Stent, lumen and neointimal volumes were calculated using Simpson's rule [22]. The percent in-stent volume obstruction $(\% \mathrm{VO})$ was calculated as follows: $\% \mathrm{VO}=100 \times($ neointimal volume $/$ stent volume). The time course of stent, lumen and neointimal volumes, and the $\% \mathrm{VO}$ were determined for each iliac artery.

\section{Statistical analysis}

Continuous values are expressed as the mean \pm SD. Variables were compared between groups using MannWhitney $U$-test. A 2-way repeated measures analysis of variance (ANOVA) was employed to test for significant differences over time. A $P$ value $<0.05$ was assumed to indicate a significant difference. All statistical analyses were performed using IBM SPSS Statistics version 19 (SPSS Inc., IBM, Somers, NY, USA).

\section{Results}

\section{Overall procedural success}

Experiments were performed in 8 miniature pigs; 4 male and 4 female, with a body weight of $25.1 \pm 3.6 \mathrm{~kg}$ and an age of $15.5 \pm 5.7$ months. Stent deployments and all follow-up procedures were successful in all of the animals. The total operation time of stent implantation was $158.3 \pm 16.6 \mathrm{~min}$ and that of the follow-up procedures was $69.2 \pm 12.7 \mathrm{~min}$. The left carotid approach was used for stent deployment, and follow-up was performed every 2 weeks for 12 weeks after stent implantation. For all 8 minipigs, the left common carotid artery was used $5.4 \pm 1.1$ times. The left carotid artery was used until the sheath insertion position reached the junction of the right and left carotid arteries; then, the remaining follow-up evaluations were performed through the right common carotid artery. A portion of the carotid artery was used that extended for approximately $10 \mathrm{~cm}$ from its origin, and this portion was located in front of the anterior tubercle of the cervical vertebrae and relatively near the body surface. It was easy to repeatedly isolate and manipulate this portion of the carotid artery. There were no complications such as massive bleeding or local infection as a consequence of the repeated surgical procedures throughout the study.

\section{Animal conditions}

The modified neurological grading scores were 0 and no symptoms of health deterioration or stroke were observed throughout the study. Body weights were also stable in all animals during the follow-up period. The values of hs-CRP and TNF-alpha were nearly constant during the study period (Fig. 1). 


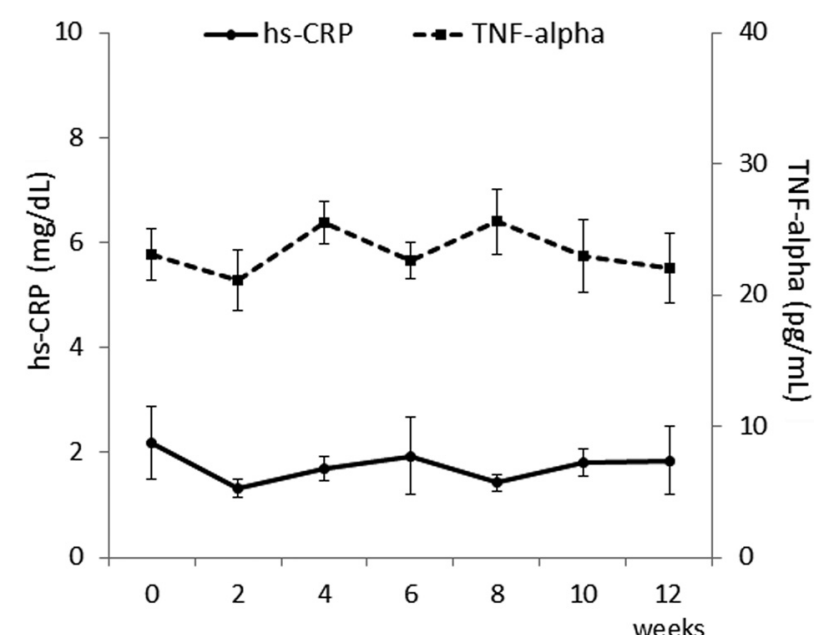

Fig. 1. The time course of plasma levels of hs-CRP and TNF-alpha. The levels of these markers were nearly constant during the study period.

\section{Quantitative IVUS results}

A total of 16 BMSs were evaluated, including 8 stents in the EIA and 8 stents in the IIA. Preoperative vessel diameter, stent size, inflation pressure and stent/artery ratio in each iliac artery are shown in Table 1. Vessel and stent diameters of EIA were larger than those of IIA. As planed, the inflation pressure and stent/artery ratio were similar between both arteries $(P>0.05)$. As a result of repeated IVUS measurements every 2 weeks for 12 weeks of follow-up, the time course of neointimal formation in each stent could be observed from the stage of hyperplasia to partial regression. Representative examples of the IIA obtained at each time point are shown in Fig. 2. In this animal, peak neointimal proliferation occurred at 10 weeks after BMS implantation. The time of peak neointimal proliferation varied considerably among animals (from 6 to 12 weeks); the mean time of the peak

Table 1. Baseline data of bare-metal stent implantation

\begin{tabular}{lccc}
\hline & External iliac artery $(\mathrm{n}=8)$ & Internal iliac artery $(\mathrm{n}=8)$ & $P$ value \\
\hline Preoperative vessel diameter, $\mathrm{mm}$ & $4.9 \pm 0.5$ & $3.6 \pm 0.3$ & $<0.0001$ \\
Stent diameter, mm & $5.3 \pm 0.5$ & $3.9 \pm 0.4$ & $<0.0001$ \\
Inflation pressure, atm & $12.0 \pm 2.5$ & $10.6 \pm 2.7$ & 0.31 \\
Stent/artery ratio & $1.08 \pm 0.05$ & $1.05 \pm 0.05$ & 0.31 \\
\hline
\end{tabular}
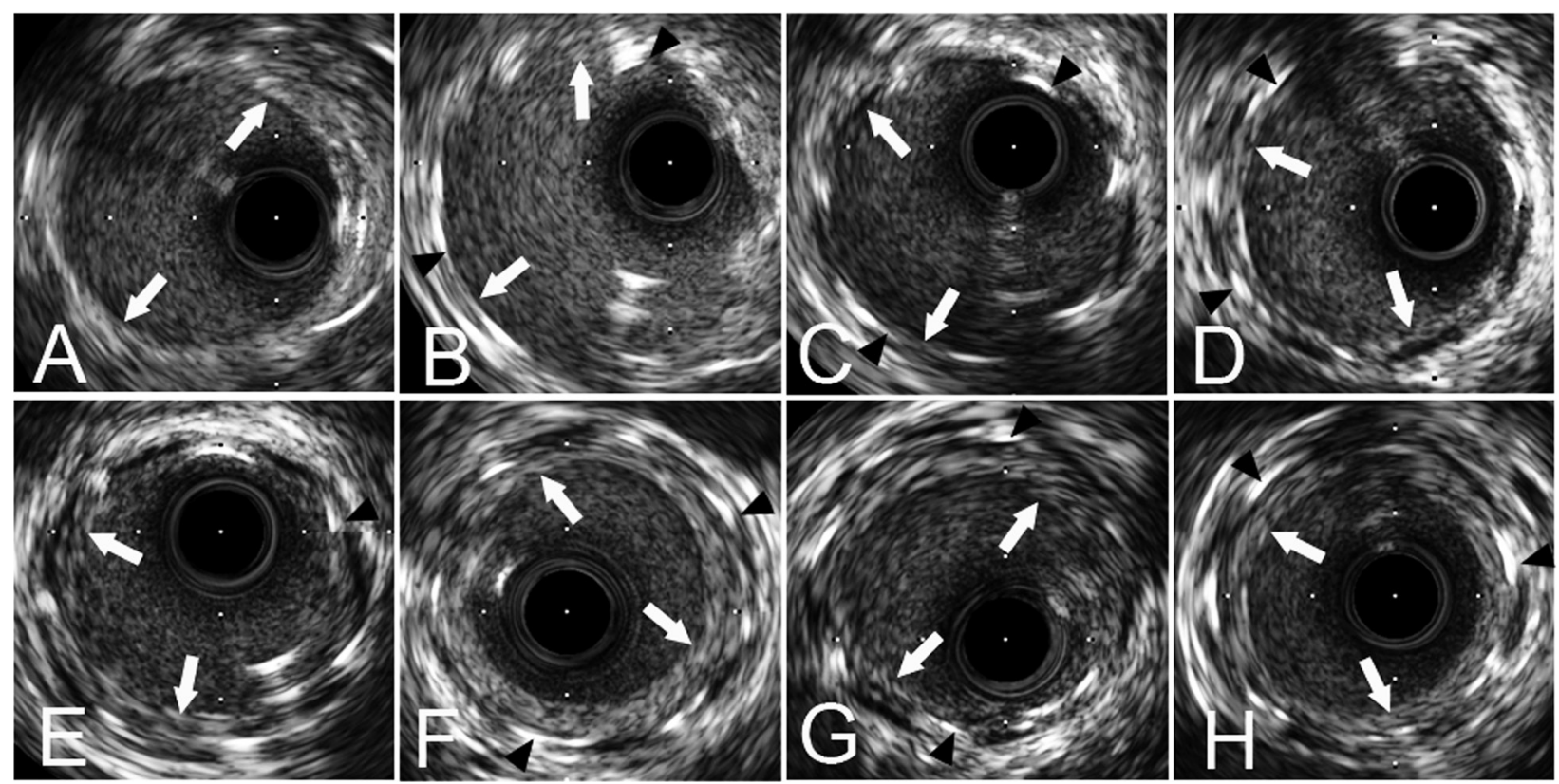

Fig. 2. Cross-sectional images obtained by repeated intravascular ultrasound (IVUS) measurements in the internal iliac artery of animal \#4. The sections shown were obtained at (A) preintervention, (B) postintervention, (C) 2 weeks, (D) 4 weeks, (E) 6 weeks, (F) 8 weeks, $(\mathrm{G}) 10$ weeks and $(\mathrm{H}) 12$ weeks. Peak neointimal proliferation occurred at 10 weeks after bare-metal stent implantation (G). White arrows show the vessel lumen borders and black arrowheads show stent struts. 


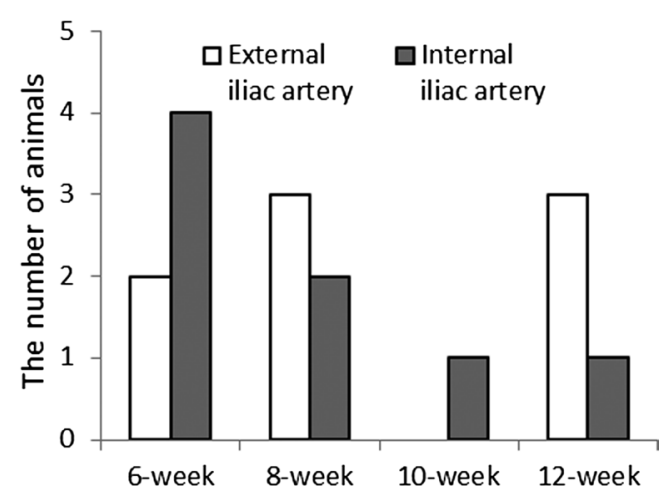

Fig. 3. The time point of peak neointimal proliferation in each iliac artery after bare-metal stent implantation. The peak time point was highly variable among animals (from 6 to 12 weeks) and was $9.0 \pm 2.6$ weeks (median, 8 weeks) in the external and $7.8 \pm 2.3$ weeks (median, 7 weeks) in the internal iliac artery.

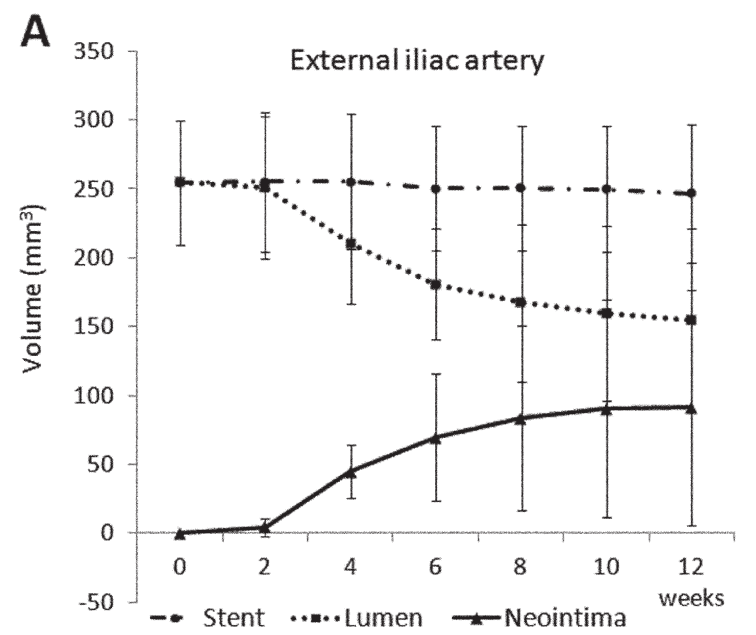

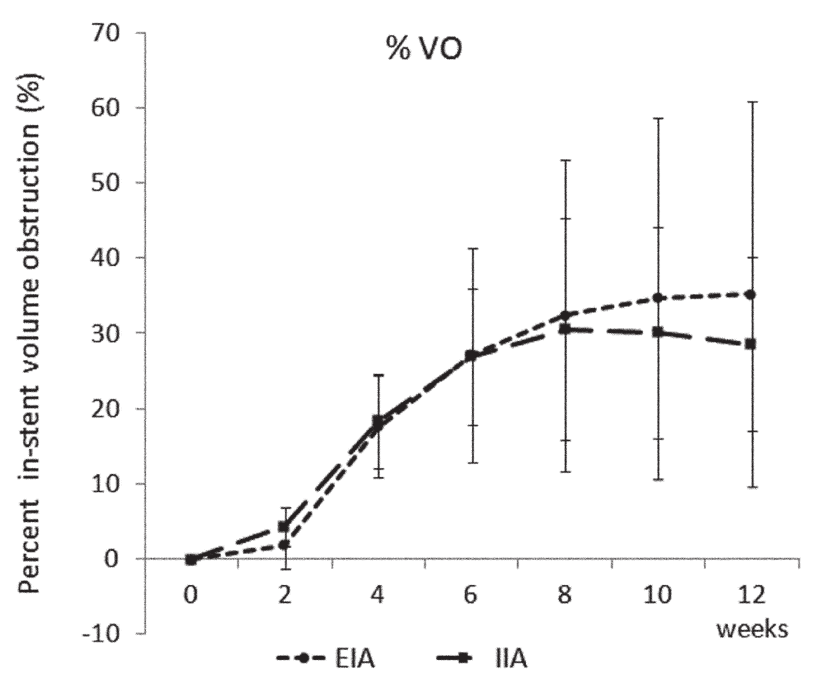

Fig. 5. The mean percent in-stent volume obstruction (\%VO) plotted over time in the external (EIA) and internal (IIA) iliac arteries. The time courses of the in-stent stenosis were similar between the EIA and IIA $(P>0.05)$. The peak values identified during 12 weeks in the EIA $(37.3 \pm 24.1 \%)$ and the IIA $(32.9 \pm 13.6 \%)$ were also similar during the study period $(P>0.05)$.

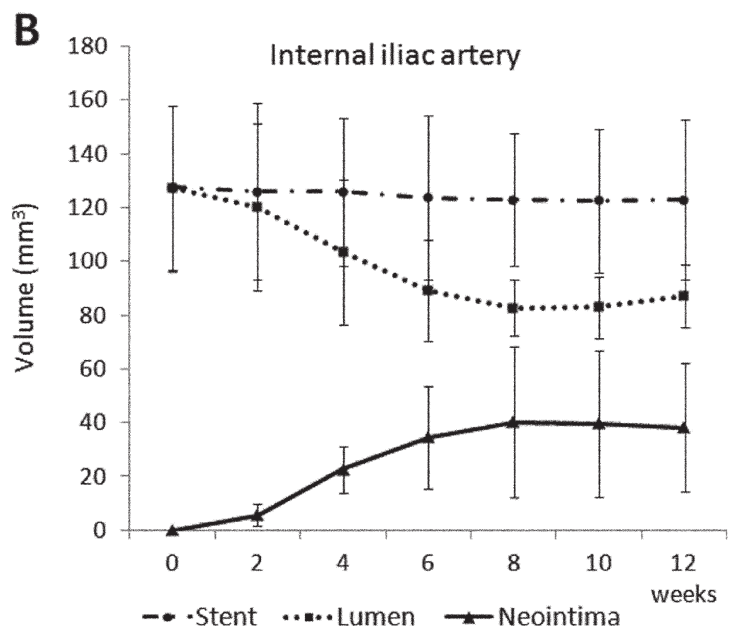

Fig. 4. The mean values of stent, lumen and neointimal volumes plotted over time in the (A) external and (B) internal iliac arteries. The values were determined by repeated intravascular ultrasound (IVUS) measurements. The morphological changes of them after bare-metal stent implantation could be evaluated in detail over time in each iliac artery.

was $9.0 \pm 2.6$ weeks (median, 8 weeks) in the EIA and $7.8 \pm 2.3$ weeks (median, 7 weeks) in the IIA (Fig. 3). The mean stent, lumen and neointimal volumes plotted over time for each iliac artery are shown in Fig. 4. These parameters followed a similar time course in both arteries after BMS implantation. The mean values of the $\%$ VO plotted over time for each iliac artery are shown in Fig. 5. The peak values identified during 12 weeks were $37.3 \pm 24.1 \%$ in the EIA and $32.9 \pm 13.6 \%$ in the IIA. The time course and peak values of $\% \mathrm{VO}$ were similar between the EIA and IIA $(P>0.05)$.

\section{Discussion}

Our model shows the feasibility of serial measurements of in-stent stenosis through repeated carotid artery 
catheterization. Despite the repeated procedures, all the animals remained in good health throughout the study period. The serial measurements allowed the time course of in-stent neointimal proliferation to be determined from the stage of neointimal hyperplasia to partial regression in the same animal. Moreover, this allowed the identification of peak neointimal proliferation. Although identical stents were implanted in the same arteries using the same deployment method, the peak time points varied considerably among individual animals. This finding shows the importance of serial measurements of neointimal formation after stent implantation. Our model also allowed the simultaneous assessment of luminal narrowing and subsequent slight luminal enlargement. Moreover, total of 4 stents can be evaluated and 2-pair side by side comparison can be performed in one animal, which is very important for reduction of animal numbers in research.

A key aspect of our method was the repeated placement of an arterial sheath-introducer in the carotid artery. In previous pig studies, the initial procedure was performed through a sheath in a femoral or carotid artery, and the artery was usually totally ligated after the procedure $[6,10,17]$. The contralateral femoral or carotid artery was used in the second and final procedure. Although there is a report that the IVUS measurements of coronary stents were repeated in the same animal three times [4], those measurements were done by catheterization of three different arteries (right femoral, left femora and right carotid). In our model, the femoral artery that is located downstream from the iliac artery could not be used, because stents were placed in the iliac arteries for symmetrical comparison of different stent types. Therefore, we decided to repeatedly catheterize the left carotid artery and then the right carotid artery (if necessary). Using this method, a total of seven procedures were performed in each animal. These repeated procedures allowed a detail assessment of the time course of neointimal proliferation. The left common carotid artery was used approximately five times without any complications. Although there were some tissue adhesions around the previously used area with each subsequent procedure, the use of anatomical landmarks helped us to identify the carotid artery before each procedure.

In conventional animal models, the data from different animals sacrificed at several time points ( 28 days, 90 days and 180 days) have been substituted for serial measurements in order to investigate the time course of in- stent stenosis $[12,14-16,18]$. However, this method assumes an identical time course of in-stent stenosis among different animals. Our results clearly show that there is a significant variation in the time course among animals. In porcine coronary and iliac artery models, peak neointimal proliferation has been typically evaluated at 28 days $[3,10,14-16]$. Although we can compare the responses at 28 days, it is unclear whether this time point accurately reflects the time of peak neointimal proliferation. The time course of neointimal proliferation should differ depending on the stent type, stent structure and deployment method [1, 8, 9, 13, 23]. In fact, despite the same stent type and deployment procedure, the time point of peak neointimal proliferation was not 28 days, varying from 6 to 12 weeks in this study. Only serial measurements in the same animal can identify the peak neointimal proliferation of each stent. Further studies using this model are in progress, and the result of a direct comparison between BMSs and new kinds of stents implanted in contralateral iliac arteries will be reported in the future.

The limitation of this study is mainly its invasiveness. In order to reduce the number of skin incision, we previously tried subcutaneous implantation of the sheath-introducer that was placed into carotid artery, which led to deteriorate animal health causing sepsis though the antibiotics was given daily. Therefore, we decided not to implant sheath-introducer but to remove the foreign materials each time. We also made effort to maintain the operative field clean by washing with a large amount of saline throughout the procedure and to shorten the operation time in order to prevent the postoperative wound infection. And also, we took care for animal comfort daily by a veterinarian's support because repetitive invasive procedures to the same animal lead to more mental and physical burdens. The intravascular procedure such as angiography and IVUS is currently gold standard method to evaluate the changes after stent implantation in human. The less invasive evaluation method, for example computed tomography and magnetic resonance imaging, will be expected to develop in the future.

Although IVUS and angiographic measurements are useful, histological examinations at multiple time points remains the gold standard for evaluating the efficacy and safety of stents in preclinical studies [12, 14, 15]. Our results show that repeated IVUS and/or angiographic measurements can be obtained as a supplemental procedure for investigating the time course of in-stent steno- 
sis. Furthermore, if the time of peak neointimal proliferation of the targeted stent could be identified in preliminary studies, it might be useful to select the optimal time point to sacrifice the animals for histological examination. Moreover, repeated carotid artery catheterization should be also useful for the serial angiographic and/or IVUS evaluation of various stent types implanted in the coronary arteries.

\section{Conclusions}

In conclusion, the serial analysis of in-stent stenosis in the iliac arteries of minipigs is feasible through repeated carotid artery catheterization. Using this method, the time course and peak neointimal proliferation can be evaluated without compromising the health of the animals.

\section{Acknowledgments}

The authors gratefully acknowledge Toru Wakui, Minoru Yamada, Kunitoshi Ito and Toshihiko Nakao for technical assistance and daily animal management.

\section{References}

1. Barth, K.H., Virmani, R., Froelich, J., Takeda, T., Lossef, S.V., Newsome, J., Jones, R., and Lindisch, D. 1996. Paired comparison of vascular wall reactions to Palmaz stents, Strecker tantalum stents, and Wallstents in canine iliac and femoral arteries. Circulation 93: 2161-2169. [Medline] [CrossRef]

2. Carter, A.J., Laird, J.R., Kufs, W.M., Bailey, L., Hoopes, T.G., Reeves, T., Farb, A., and Virmani, R. 1996. Coronary stenting with a novel stainless steel balloon-expandable stent: determinants of neointimal formation and changes in arterial geometry after placement in an atherosclerotic model. J. Am. Coll. Cardiol. 27: 1270-1277. [Medline] [CrossRef]

3. Carter, A.J., Laird, J.R., Farb, A., Kufs, W., Wortham, D.C., and Virmani, R. 1994. Morphologic characteristics of lesion formation and time course of smooth muscle cell proliferation in a porcine proliferative restenosis model. J. Am. Coll. Cardiol. 24: 1398-1405. [Medline] [CrossRef]

4. Fröhlich, G., Strehblow, C., Sperker, W., Yahya, N., Shirazi, M., Hevesi, A., Garamvölgyi, R., Hadjiev, J., Scherzer, T., Glogar, D., and Gyöngyösi, M. 2003. Serial intravascular ultrasonographic measurements after implantation of biodegradable polymer-coated stents in porcine coronary arteries. Coron. Artery Dis. 14: 409-412. [Medline] [CrossRef]

5. Galloni, M., Prunotto, M., Santarelli, A., Laborde, F., Dibie, A., Isaia, C., Monari, E., Gatti, A.M., and Pasquino, E. 2003. Carbon-coated stents implanted in porcine iliac and renal arteries: histologic and histomorphometric study. J. Vasc.
Interv. Radiol. 14: 1053-1061. [Medline] [CrossRef]

6. Henn, C., Satzl, S., Christoph, P., Kurz, P., Radeleff, B., Stampfl, U., Stampfl, S., Berger, I., and Richter, G.M. 2008. Efficacy of a polyphosphazene nanocoat in reducing thrombogenicity, in-stent stenosis, and inflammatory response in porcine renal and iliac artery stents. J. Vasc. Interv. Radiol. 19: 427-437. [Medline] [CrossRef]

7. Hoffmann, R., Mintz, G.S., Dussaillant, G.R., Popma, J.J., Pichard, A.D., Satler, L.F., Kent, K.M., Griffin, J., and Leon, M.B. 1996. Patterns and mechanisms of in-stent restenosis. A serial intravascular ultrasound study. Circulation 94: 1247-1254. [Medline] [CrossRef]

8. Kastrati, A., Schömig, A., Dietz, R., Neumann, F.J., and Richardt, G. 1993. Time course of restenosis during the first year after emergency coronary stenting. Circulation 87 : 1498-1505. [Medline] [CrossRef]

9. Schürmann, K., Vorwerk, D., Kulisch, A., Stroehmer-Kulisch, E., Biesterfeld, S., Stopinski, T., and Günther, R.W. 1995. Experimental arterial stent placement. Comparison of a new Nitinol stent and Wallstent. Invest. Radiol. 30: 412420. [Medline] [CrossRef]

10. Lowe, H.C., Schwartz, R.S., Mac Neill, B.D., Jang, I.K., Hayase, M., Rogers, C., and Oesterle, S.N. 2003. The porcine coronary model of in-stent restenosis: current status in the era of drug-eluting stents. Catheter. Cardiovasc. Interv. 60: 515-523. [Medline] [CrossRef]

11. Mintz, G.S., Nissen, S.E., Anderson, W.D., Bailey, S.R., Erbel, R., Fitzgerald, P.J., Pinto, F.J., Rosenfield, K., Siegel, R.J., Tuzcu, E.M., and Yock, P.G. 2001. American college of cardiology clinical expert consensus document on standards for acquisition, measurement and reporting of intravascular ultrasound studies (IVUS). A report of the american college of cardiology task force on clinical expert consensus documents. J. Am. Coll. Cardiol. 37: 1478-1492. [Medline] [CrossRef]

12. Nakazawa, G., Finn, A.V., John, M.C., Kolodgie, F.D., and Virmani, R. 2007. The significance of preclinical evaluation of sirolimus-, paclitaxel-, and zotarolimus-eluting stents. Am. J. Cardiol. 100:(8B): 36M-44M. [Medline] [CrossRef]

13. Nakazawa, G., Finn, A.V., Joner, M., Ladich, E., Kutys, R., Mont, E.K., Gold, H.K., Burke, A.P., Kolodgie, F.D., and Virmani, R. 2008. Delayed arterial healing and increased late stent thrombosis at culprit sites after drug-eluting stent placement for acute myocardial infarction patients: an autopsy study. Circulation 118: 1138-1145. [Medline] [CrossRef]

14. Schwartz, R.S., Edelman, E.R., Carter, A., Chronos, N., Rogers, C., Robinson, K.A., Waksman, R., Weinberger, J., Wilensky, R.L., Jensen, D.N., Zuckerman, B.D., Virmani, R., Consensus Committee 2002. Drug-eluting stents in preclinical studies: recommended evaluation from a consensus group. Circulation 106: 1867-1873. [Medline] [CrossRef]

15. Schwartz, R.S., Edelman, E., Virmani, R., Carter, A., Granada, J.F., Kaluza, G.L., Chronos, N.A., Robinson, K.A., Waksman, R., Weinberger, J., Wilson, G.J., and Wilensky, R.L. 2008. Drug-eluting stents in preclinical studies: updated consensus recommendations for preclinical evaluation. Circ. Cardiovasc. Interv. 1: 143-153. [Medline] [CrossRef]

16. Schwartz, R.S., Edelman, E.R., Carter, A., Chronos, N.A., 
Rogers, C., Robinson, K.A., Waksman, R., Machan, L., Weinberger, J., Wilensky, R.L., Goode, J.L., Hottenstein, O.D., Zuckerman, B.D., and Virmani, R. 2004. Preclinical evaluation of drug-eluting stents for peripheral applications: recommendations from an expert consensus group. Circulation 110: 2498-2505. [Medline] [CrossRef]

17. Schwartz, R.S., Murphy, J.G., Edwards, W.D., Camrud, A.R., Vliestra, R.E., and Holmes, D.R. 1990. Restenosis after balloon angioplasty. A practical proliferative model in porcine coronary arteries. Circulation 82: 2190-2200. [Medline] [CrossRef]

18. Suzuki, Y., Yeung, A.C., and Ikeno, F. 2009. The pre-clinical animal model in the translational research of interventional cardiology. JACC Cardiovasc. Interv. 2: 373-383. [Medline] [CrossRef]

19. Tanaka, M., Tsuno, N.H., Mitsudo, K., Kadota, K., Tatami, R., Kato, M., Kato, K., Nogami, A., Ishikawa, O., and Takahashi, K. 2011. First human trial of KW39 slotted-tube stents: for percutaneous coronary intervention. Tex. Heart Inst. J. 38: 502-507. [Medline]

20. Tanaka, Y., Imai, H., Konno, K., Miyagishima, T., Kubota, C., Puentes, S., Aoki, T., Hata, H., Takata, K., Yoshimoto, Y., and Saito, N. 2008. Experimental model of lacunar infarction in the gyrencephalic brain of the miniature pig: neurological assessment and histological, immunohistochemical, and physiological evaluation of dynamic corticospinal tract deformation. Stroke 39: 205-212. [Medline] [CrossRef]

21. von Birgelen, C., Gil, R., Ruygrok, P., Prati, F., Di Mario, C., van der Giessen, W.J., de Feyter, P.J., and Serruys, P.W. 1996. Optimized expansion of the Wallstent compared with the Palmaz-Schatz stent: on-line observations with two- and three-dimensional intracoronary ultrasound after angiographic guidance. Am. Heart J. 131: 1067-1075. [Medline] [CrossRef]

22. Weissman, N.J., Wilensky, R.L., Tanguay, J.F., Bartorelli, A.L., Moses, J., Williams, D.O., Bailey, S., Martin, J.L., Canos, M.R., Rudra, H., Popma, J.J., Leon, M.B., Kaplan, A.V., and Mintz, G.S. 2001. Extent and distribution of in-stent intimal hyperplasia and edge effect in a non-radiation stent population. Am. J. Cardiol. 88: 248-252. [Medline] [CrossRef]

23. Wilson, G.J., Nakazawa, G., Schwartz, R.S., Huibregtse, B., Poff, B., Herbst, T.J., Baim, D.S., and Virmani, R. 2009. Comparison of inflammatory response after implantation of sirolimus- and paclitaxel-eluting stents in porcine coronary arteries. Circulation 120: 141-149, 1-2. [Medline] [CrossRef]

24. Yamaguchi, M., Zhou, C., Heistad, D.D., Watanabe, Y., and Zhang, J.H. 2004. Gene transfer of extracellular superoxide dismutase failed to prevent cerebral vasospasm after experimental subarachnoid hemorrhage. Stroke 35: 2512-2517. [Medline] [CrossRef] 